\section{Cellular Physiolosy and Biochemistry}

\title{
The Temperature-Sensitive Ion Channel TRPV2 is Endogenously Expressed and Functional in the Primary Sensory Cell Line F-11
}

\author{
Florian L.P. Bender ${ }^{1,2^{*}}$, Michael Mederos y Schnitzler ${ }^{*}$, Yanzhang \\ $\mathrm{Li}^{1}$, Ailing Ji ${ }^{1}$, Eberhard Weihe ${ }^{1}$, Thomas Gudermann², Martin K.-H. \\ Schäfer ${ }^{1}$
}

${ }^{1}$ Molecular Neuroscience, Institute of Anatomy and Cell Biology, ${ }^{2}$ Institute of Pharmacology and Toxicology, Philipps University Marburg, *Both authors contributed equally to this work

\section{Key Words}

Nociception - Temperature - Vanilloid receptor • Noxious heat $\cdot$ Ruthenium red $\cdot$ Dorsal root ganglion

\begin{abstract}
In sensory neurons heat is transduced by a subfamily of TRP channels sharing sequence homology with the capsaicin-sensitive vanilloid receptor subtype 1 (TRPV1), but differing in their thermal response thresholds. To identify a neuronal cell line endogenously expressing noxious heat-transducing ion channels, we examined F-11 cells, a hybridoma derived from rat dorsal root ganglia and mouse neuroblastoma. Using RT-PCR, transcripts homologous to TRPV2 and TRPV4, but not to TRPV1 or TRPV3, were found. We isolated a full-length cDNA of $2.4 \mathrm{~kb}$ coding for a 757-amino acid protein corresponding to mouse TRPV2, which was further characterized by immunocytochemistry and electrophysiology. Using the whole-cell patch-clamp technique, we observed a heat-evoked increase in outward and inward currents with a threshold of 51.6 $\pm 0.2^{\circ} \mathrm{C}$. The current-voltage relationship stimulated by a temperature of $52^{\circ} \mathrm{C}$ was characterized by an outward rectification with a reversal potential close to
\end{abstract}

\section{KARGER}

Fax +4161306 1234

E-Mail karger@karger.ch

www.karger.com
(C) 2005 S. Karger AG, Basel

1015-8987/05/0154-0183\$22.00/0

Accessible online at:

www.karger.com/journals/net
$-10 \mathrm{mV}$. Heat-evoked currents could be inhibited by ruthenium red. There was no activation by stimulation with capsaicin or 2-aminoethoxydiphenyl borate. Our results indicate that $\mathrm{F}-11$ cells express functional noxious heat-sensitive TRPV2 channels. Thus, we propose that $\mathrm{F}-11$ cells represent a valuable in vitro model to characterize the properties of TRPV2 in a native neuronal environment.

Copyright () 2005 S. Karger AG, Basel

\section{Introduction}

TRP (transient receptor potential) ion channels represent a large superfamily of non-voltage-gated cation channels that display a remarkable diversity of activation mechanisms [1]. Members of the vanilloid receptor family (TRPV) are activated by a wide range of stimuli, including temperature, protons, phorbol esters, lipids, changes in extracellular osmolarity and pressure, and depletion of intracellular $\mathrm{Ca}^{2+}$ stores $[2,3]$. The temperature-sensitive TRPV channels (TRPV1 to TRPV4) differ in their thermal response thresholds and have a unique cellular distribution pattern in distinct subpopulations of primary sensory neurons [4]. 
TRPV1, the first identified thermosensitive TRP channel, also known as vanilloid receptor subtype 1(VR1), is expressed in a subpopulation of noxious heat-sensitive primary afferents characterized as mainly small-diameter $\mathrm{C}-$ and thinly myelinated A $\delta$ fibers [5]. These TRPV1expressing type II fibers are capsaicin-sensitive and can be activated by low-threshold $\left(43^{\circ} \mathrm{C}\right)$ thermal stimuli, protons [5] and endogenous lipid signalling molecules such as anandamide [6] and eicosanoids [7]. TRPV1 has been shown to be coexpressed with TRPV3 (also known as VRL3), another member of the TRP gene family, which is heat-sensitive with a threshold of about $39^{\circ} \mathrm{C}$, but capsaicin-insensitive [8]. TRPV3 is able to associate with TRPV1 to form heteromeric vanilloid receptor channels.

A second class of thermosensitive sensory neurons are the medium- to large-diameter A $\delta$ mechano- and heatsensitive (AMH) neurons which have a high thermal response threshold of $\sim 53^{\circ} \mathrm{C}$ [9] and express the TRPV2 ion channel, formerly named VRL-1 $[10,11]$. The rat 761 -amino acid TRPV2 protein is $82 \%$ identical to the mouse 757 -amino acid protein and $78 \%$ identical to human TRPV2. Unlike TRPV1, TRPV2 is not activated by capsaicin, acid or moderate heat, but does respond to noxious heat at temperatures above $52^{\circ} \mathrm{C}$ [10].

Electrophysiological characterization of heatsensitive TRPV channels has initially relied on heterologous expression in cell lines of non-neuronal origin lacking the physiological properties of sensory neurons, thus introducing a certain bias with respect to the in vivo relevance of the results obtained [4]. Therefore, a primary sensory neuronal cell line with endogenous expression of heat-sensitive TRPV channels would be advantageous to study the cellular and molecular mechanisms of heatevoked signal transduction. Previously, modulation of voltage-gated $\mathrm{Ca}^{2+}$ currents by pain inducing agents including capsaicin, bradykinin and resiniferotoxin was reported for the dorsal root ganglion neuronal line F-11 [12]. As a fusion product of embryonic rat dorsal root ganglion cells with the mouse neuroblastoma cell line N18TG-2 [13], F-11 cells have retained certain traits of sensory DRG neurons $[14,15]$. Therefore, we embarked on the molecular and functional characterization of heatsensitive ion channels in F-11 cells, presently considered as one of the suitable neuronal cell lines to study properties of sensory neurons. While this paper was in preparation the expression of TRPV2 in F-11 cells and its biochemical characterization was reported by Jahnel et al. [16], but the functional characterization of TRPV2 was still unresolved.

\section{Materials and Methods}

\section{Animals}

200-225 g male Wistar rats and 20-25 g male BALB/c mice (Charles River, Sulzfeld, Germany) were housed in clean plastic cages with food and water available ad libidum. Animals were kept on a $12 \mathrm{~h}: 12 \mathrm{~h}$ light dark cycle. After killing by exposure to $\mathrm{CO}_{2}$, dorsal root ganglia, brains and tails were rapidly removed and frozen immediately in liquid nitrogen for RNA extraction. All experimental protocols in this study were reviewed and approved by the local Animal Care and Use Committee and are in accordance with the National Institutes of Health Guide for the Care and Use of Laboratory Animals.

\section{Cell culture}

The rat dorsal root ganglion/mouse neuroblastoma hybridoma cell line F-11 (N18TG2) was provided by Dr. Mark C. Fishman (Massachusetts General Hospital - Harvard Medical School, Boston, Massachusetts, USA). F-11 cells were grown in Ham's F12 medium with Glutamax, supplemented with 15\% Hyclone-defined fetal bovine serum, 2\% hypoxanthin/ thymidine HAT supplement and $1 \mathrm{x}$ antibiotic-antimycotic mixture at $37^{\circ} \mathrm{C}$ in a humidified $5 \% \mathrm{CO}_{2}$ incubator. All cell culture reagents were purchased from GibcoBRL (Karlsruhe, Germany). At approximately $70-80 \%$ confluence, cells were harvested for RNA or protein extraction.

For primary culture, dorsal root ganglia were rapidly removed from neonatal rats in calcium/magnesium-free medium. After incubation with $0.075 \%$ collagenase and $0.15 \%$ dispase for 45 minutes followed by $0.125 \%$ trypsin, ganglia were dissociated and cultured in DMEM with 10\% FCS (Sigma, USA), Glutamax and antibiotic-antimycotic mixture at $37^{\circ} \mathrm{C}$ under $5 \%$ $\mathrm{CO}_{2}$.

\section{RNA isolation}

Total RNA was isolated from pooled DRG and F-11 cells using TRIzol Reagent (GibcoBRL, Karlsruhe, Germany) and treated with RNase-free DNase I (Roche Diagnostics, Mannheim, Germany) at $37^{\circ} \mathrm{C}$ for $30 \mathrm{~min}$ and purified using RNeasy Mini Kits (QIAGEN, Hilden, Germany). Poly (A) mRNA was prepared using a Poly (A) Tract mRNA Isolation system III (Promega, Mannheim, Germany) according to the manufacturer's protocol.

\section{$R T-P C R$}

cDNA was synthesized in a total volume of $20 \mu \mathrm{l}$ containing $2.5 \mu \mathrm{g}$ total RNA from rat DRG or F-11 cells, $1.25 \mu \mathrm{M}$ oligo (dT) 12-18 (Amersham Pharmacia Biotech, Freiburg, Germany), $10 \mathrm{mM}$ dithiothreitol (DTT) , 200 U SUPERSCRIPT II RNase H-Reverse Transcriptase (GibcoBRL, Karlsruhe, Germany), 0.5 mM dNTPs, and first strand buffer (GibcoBRL, Karlsruhe, Germany). After a 1 -h incubation at $42^{\circ} \mathrm{C}$ and $5 \mathrm{~min}$ at $94^{\circ} \mathrm{C}$ to inactivate the enzyme, reactions were diluted to $50 \mu 1$ by adding $30 \mu \mathrm{lPCR}$ grade water and stored at $-20^{\circ} \mathrm{C}$. Hot start PCR was performed on a GeneAmp 9700 cycler (Perkin Elmer, Weiterstadt, Germany) using $5 \mu \mathrm{l}$ cDNA in a total volume of 50

Bender/Schnitzler/Li/Ji/Weihe/Gudermann/Schafer 
$\mu 1$, containing forward and reverse primers ( $0.2 \mu \mathrm{M}$ of each), $1 \mathrm{x}$ PCR buffer, $1.5 \mathrm{mM} \mathrm{MgCl}_{2}, 200 \mu \mathrm{M}$ dNTP mixture and $1 \mathrm{U}$ AmpliTaq Gold (Roche Diagnostics, Mannheim, Germany). All primers were custom-synthesized by MWG Biotech (Munich, Germany). A 828-bp rat TRPV1 fragment (AF029310, nt. 15-842) was amplified by forward primer 5'-ttg ctc cat ttg ggg tgt gc-3' and reverse primer 5'-cag gga cag ggg cag ctc ac-3' at an annealing temperature of $60^{\circ} \mathrm{C}$. A 452-bp TRPV2 fragment (XM_126241, nt. 2154-2605) was amplified by forward primer 5' -gct gtt caa gtt cac cat tg-3' and reverse primer 5' -cct ctg agg cac tgt tct tc-3' at an annealing temperature of $59^{\circ} \mathrm{C}$. A 550-bp TRPV3 fragment (NM_145099, nt. 98-647) was amplified by forward primer 5'-atg ggc aaa aga acc acg gc-3' and reverse primer 5'-cag cga agg caa gca gaa tc-3' at an annealing temperature of $57^{\circ} \mathrm{C}$. A 183-bp TRPV4 fragment (NM_023970, nt. 283-465) was amplified by forward primer 5'-cgt cca aac ctg cga atg aag ttc-3' and reverse primer 5'-cct cca tct ctt gtt gtc act gg-3' at an annealing temperature of $57^{\circ} \mathrm{C}$. To determine rat or mouse origin of F-11 TRPV2 mRNAs RT-PCR amplification was performed by forward primer 5'-ggc aat get gag gtg aac aa-3' and reverse primer 5' -ccg ctc cat tct cta cca-3'. RNA subjected to RT-PCR without reverse transcriptase served as a negative control. $10 \mu \mathrm{l}$ of each PCR reaction were loaded and electrophoresed on $1.5 \%$ agarose gels containing ethidium bromide and visualized by ultraviolet transillumination (BioRad, Munich, Germany).

\section{Cloning of TRPV2 from F-11 cells}

Full length cDNAs were isolated from F-11 cellular extracts by PCR cloning using Pfu DNA polymerase. PCR products were subcloned into the pCR3.1 Vector (Invitrogen, Karlsruhe, Germany) used to transform Top10F' competent cells (Invitrogen, Karlsruhe, Germany). Plasmids were isolated by a QIAfilter Plasmid Maxi Kit (QIAGEN, Hilden, Germany) and subjected to double-stranded DNA sequencing with universal primer $\mathrm{T} 7$ and $\mathrm{BGH}$ reverse sequence primer as well as genespecific primers.

\section{Genomic PCR}

Genomic DNA was isolated from F-11 cells as well as from mouse and rat tail tip biopsies and $200 \mathrm{ng}$ were used for PCR with mouse and rat specific TRPV2 primer pairs. A 486-bp mouse TRPV2 fragment was amplified by a forward primer corresponding to the exon 3 region 5'-act ggg tcc cag gtg agg cta-3' of the mouse TRPV2 gene (Ensemble Gene ID: ENSMUSG0000018507) and a reverse primer mTRPV2 corresponding to the intron III region 5 '-caa ccc atg agg att ctg gg-3' at an annealing temperature of $59^{\circ} \mathrm{C}$. A 474-bp rat TRPV2 fragment was amplified by a forward primer rTRPV2 corresponding to the exon 1 region 5'-gac ctc cta aaa aca ctt ctg ctc c-3' of the rat TRPV2 gene (Ensemble ID: ENSRNOG00000003104) and a reverse primer rTRPV2 corresponding to the intron I region 5' -cac agg aaa ctc aaa ctg cag atg a-3' at an annealing temperature of $59^{\circ} \mathrm{C}$.

\section{Northern Blot Analysis}

A rat TRPV2 cRNA probe was generated by in vitro transcription from a pGEM-T plasmid construct containing a 996-bp fragment of rat TRPV2 (NM_017207,nt_991-1986) using ${ }^{32} \mathrm{P}-U T P$ ( $>3000 \mathrm{Ci} / \mathrm{mmol}$, Amersham Pharmacia Biotech, Freiburg, Germany) as a radioactive label for Northern blotting. Reactions were performed in a volume of $5 \mu \mathrm{l}$ containing $0.6 \mu \mathrm{g}$ linearized plasmids, $20 \mathrm{U}$ RNase inhibitor, 1x buffer, $100 \mathrm{U}$ SP6 RNA polymerase, $0.5 \mathrm{mM}$ NTP mixture with ${ }^{32} \mathrm{P}$-labeled UTP After a $90 \mathrm{~min}$ incubation at $37^{\circ} \mathrm{C}, 5 \mathrm{U}$ RNase-free DNase I were added to the reaction mixtures, incubated for another $15 \mathrm{~min}$ and subsequently purified by Micro Bio-Spin P-30 columns. Poly (A)-RNA from rat DRG and F-11 cells ( $1 \mu \mathrm{g}$ each) were size-fractionated on $1.5 \%$ agarose, transferred onto a nylon membrane and UV cross-linked (Stratagene, Amsterdam, The Netherlands). Membranes were prehybridized with NorthernMax solution (Ambion, Cambridgeshire, UK) at $68^{\circ} \mathrm{C}$ for $30 \mathrm{~min}$ and hybridized with $5 \times 10^{6} \mathrm{cpm} / \mathrm{ml}$ rat TRPV2 cRNA probes at $68^{\circ} \mathrm{C}$ overnight. After washing twice for $5 \mathrm{~min}$ with 2 $\mathrm{x}$ SSC containing $0.1 \%$ SDS and twice for 15 min with $0.1 \times$ SSC containing $0.1 \% \mathrm{SDS}$ at $68^{\circ} \mathrm{C}$, membranes were exposed to Hyperfilm-MP (Amersham Pharmacia Biotech, Freiburg, Germany) for $1 \mathrm{~h}$.

\section{Immunocytochemistry}

Confocal laser-scanning double-immunofluorescence microscopy was performed as previously described $[17,18]$. In brief, deparaffinized frontal serial sections of adult DRG fixed in Bouin-Hollande solution were incubated at room temperature overnight with the biotin labeled isolectin B4 (IB4) from Bandeiraea simplicifolia (Sigma, 1:20 dilution) together with either a polyclonal affinity-purified rabbit antibody recognizing TRPV2 (Chemicon, Temecula, USA, 1:800 dilution) or a polyclonal rabbit antibody raised against the $\mathrm{C}$ terminus of rat TRPV1 (custom synthesis from Eurogentec, Belgium, 1:800 dilution). Immunoreactivities were visualized with indocarbocyanine(Cy3)-conjugated species-specific secondary antibodies (Dianova, Hamburg, Germany) diluted 1:200 $\left(45 \mathrm{~min}, 37^{\circ} \mathrm{C}\right)$, resulting in a red-orange fluorescence labeling, or with Alexa 488-conjugated streptavidin (MoBiTec, Göttingen, Germany) at $37^{\circ} \mathrm{C}$ for $2 \mathrm{~h}$, resulting in green fluorescence. Sections were analyzed with an Olympus Fluoview confocal laser-scanning microscope (Olympus Optical) and documented as false-color confocal images.

F-11 cells grown on coverslips were washed with PBS and fixed with $4 \%$ paraformaldehyde/PBS. After washing with water, cells were stained with DAPI (Boehringer Mannheim, Germany). After a 2-h blocking step with 0,3\% triton X100, 5\% bovine serum albumine (Serve, Germany), 0.01\% sodium azide (Merck, Germany) and 5\% gelatin (Sigma, USA) in PBS, cells were incubated with the primary antibodies for TRPV1 and TRPV2 diluted in 1\% BSA-PBS. After several washing steps cells were incubated with indocarbocyanine (Cy3)-conjugated rabbit-specific secondary antibodies diluted $1: 200\left(45 \mathrm{~min}, 37^{\circ} \mathrm{C}\right)$. Cells were analyzed with the Olympus AX70 fluorescence 
microscope (Olympus Optical) and results documented with a digital Spot Camera (RT Slider, Diagnostics Instruments Inc.) and Spot image analysis software (Version 3.4, Diagnostics Instruments Inc.).

Electrophysiological analysis of F-11 cells and heterologously expressed TRPV2

Patch-clamp recordings were performed on F-11 cells (passage 4 to 25) and transiently transfected HEK293 cells, cultured in EMEM with 10\% fetal bovine serum (PAA, Linz, Austria) and co-transfected with $2 \mu \mathrm{g}$ mouse TRPV2 or rTRPV1 plasmid and $0.1 \mu \mathrm{g}$ enhanced green fluorescence reporter plasmid by lipofection. F-11 cells and transfected HEK293 cells were dispersed by treatment with $0.5 \mathrm{mg} / \mathrm{ml}$ trypsin and $0.2 \mathrm{mg}$ / $\mathrm{ml}$ EDTA for $<30 \mathrm{~s}$. Cells were allowed to adhere to cell culture dishes (No. 150318, Nunc, Roskilde, Denmark) and used within $8 \mathrm{~h}$.

Patch-clamp recordings were carried out on the stage of an inverted microscope (Olympus IX 70) at $32-37^{\circ} \mathrm{C}$ unless noted otherwise. Fast temperature ramps $\left(0.5-1^{\circ} \mathrm{C} \mathrm{s}^{-1}\right)$ from 32 to $54^{\circ} \mathrm{C}$ were generated by heating the bath solution in a temperature chamber and over a Liebig cooling device connected to a thermostat. Temperature in the proximity of the recorded cell was measured with a small thermo sensor (GTF 300, NiCr-Ni (type K) and GTH 1200A, Greisinger, Regenstauf, Germany) and digitized by an EPC9 amplifier and Pulse software. Adherent cells were superfused in a cell culture dish mounted to a small perfusion chamber with the following extracellular solution (mM): $\mathrm{NaCl} 140, \mathrm{CsCl} 5, \mathrm{CaCl}_{2} 2, \mathrm{MgCl}_{2}$ 1, glucose 10 , HEPES 10, titrated to $\mathrm{pH} 7.4$ with $\mathrm{NaOH}$. Data of conventional whole-cell recordings were collected with an EPC9 patch-clamp amplifier (HEKA, Lambrecht, Germany) using the Pulse software (HEKA). Patch pipettes made of borosilicate glass (Science Products, Hofheim, Germany) displayed resistances of 2.2 to $3.5 \Omega$ when filled with the intracellular solution (mM): $\mathrm{CsCl} 120, \mathrm{NaCl} 9.4, \mathrm{MgCl}_{2} 1$, buffered at $100 \mathrm{nM}$ free $\mathrm{Ca}^{2+}$ with BAPTA 10, HEPES 10, titrated to $\mathrm{pH} 7.2$ with $\mathrm{CsOH}$. The liquid junction potential was $+4.2 \mathrm{mV}$ and offset correction was made by the Pulse software. Series resistance was compensated to $70 \%$. Cells were held at $-60 \mathrm{mV}$, and current-voltage relations were obtained from triangular voltage ramps from -100 to +60 $\mathrm{mV}$ with a slope of $0.4 \mathrm{~V} \mathrm{~s}^{-1}$ applied at a frequency of $1 \mathrm{~Hz}$. Data were acquired at a frequency of $5 \mathrm{kHz}$ after filtering at $1.67 \mathrm{kHz}$. All chemicals for intracellular and extracellular solutions were from Sigma (Taufkirchen, Germany).

\section{Pharmacological analysis}

To assess voltage-dependent $\mathrm{Ca}^{2+}$ currents activated by depolarising steps to $0 \mathrm{mV} 10 \mu \mathrm{M}$ nifedipine was added to the standard extracellular solution. To block TRPV channel activity, experiments were performed in the presence of $100 \mathrm{nM}$ or 10 $\mu \mathrm{M}$ ruthenium red (Sigma, Taufkirchen, Germany). To test for the possible expression of TRPV1 in F-11 and mouse TRPV2transfected HEK293 cells, $100 \mu \mathrm{M}$ capsaicin (0462, Tocris, Ellisville, USA) was added. Effects of chemical TRPV channel activation was examined by adding $100 \mu \mathrm{M}$ or $3 \mathrm{mM} 2$ aminoethoxydiphenyl borate (2-APB) (Merck Biosciences, Schwalbach/Taunus, Germany).

\section{Results}

Identification of TRPV2 in F-11 cells

We searched for expression of TRPV channels in total RNA extracts from F-11 cells using reversetranscription PCR. Specific amplicons for TRPV2 and for TRPV4 only could be detected in F-11 cells, while RNA transcripts of the capsaicin-sensitive TRPV1, which is highly expressed in rat DRG, and of TRPV3, which is present at low levels in DRG and has been shown to associate with TRPV1 [8], were absent (Fig. 1A). Six cDNAs were isolated from F-11 cellular extracts using PCR cloning and subjected to double-stranded DNA sequencing. The cDNA sequence of F-11-derived TRPV2 was submitted to Genbank (Acc. No. AY487844). DNA sequence comparison revealed that five out of the six isolated cDNAs had $100 \%$ and $93 \%$ sequence identity to mouse (XM_126241) and rat (NM_017207) TRPV2, respectively. Only one cDNA was $100 \%$ identical with rat TRPV2 (NM_017207). To determine the species specificity of TRPV 2 transcripts in F-11 cells, we performed PCR experiments using reverse transcribed RNA and genomic DNA. Amplification of the 5' end of the TRPV2-coding sequence, which is 16 nucleotides longer in rat as compared to mouse, and subsequent analysis by nondenaturing PAGE revealed that $\mathrm{F}-11$ cells predominantly express the shorter, mouse-specific TRPV2 transcript (Fig. 1B). Using specific primers for the mouse TRPV2 gene PCR amplification of genomic DNA from F-11 and mouse yielded a 486-bp amplicon corresponding to a region between exon 3 and intron III of the mouse gene confirming the RT-PCR results (Fig. 1C). A 474-bp amplicon corresponding to a region between exon 1 and intron I of the rat TRPV2 gene could not be detected in PCR reactions with F-11 genomic DNA. Using a specific TRPV2 riboprobe, a single $2.7 \mathrm{~kb}$ transcript was detected by Northern blot analysis in poly(A) RNA of F-11 cells as well as of rat DRGs (Fig. 2).

\section{Detection of TRPV2 protein in F-11 cells and} dorsal root ganglia

To demonstrate that TRPV2 RNA is translated we performed Western blot analysis and immunofluorescence with an affinity-purified polyclonal antibody against rat TRPV2, which detects the mouse protein as well. A single band of approximately $80 \mathrm{kDa}$ was detected which disappeared by preabsorption blocking of the primary antibody (data not shown). F-11 cells exhibited positive immunostaining for TRPV2 as illustrated in Fig. 3.

Bender/Schnitzler/Li/Ji/Weihe/Gudermann/Schafer 


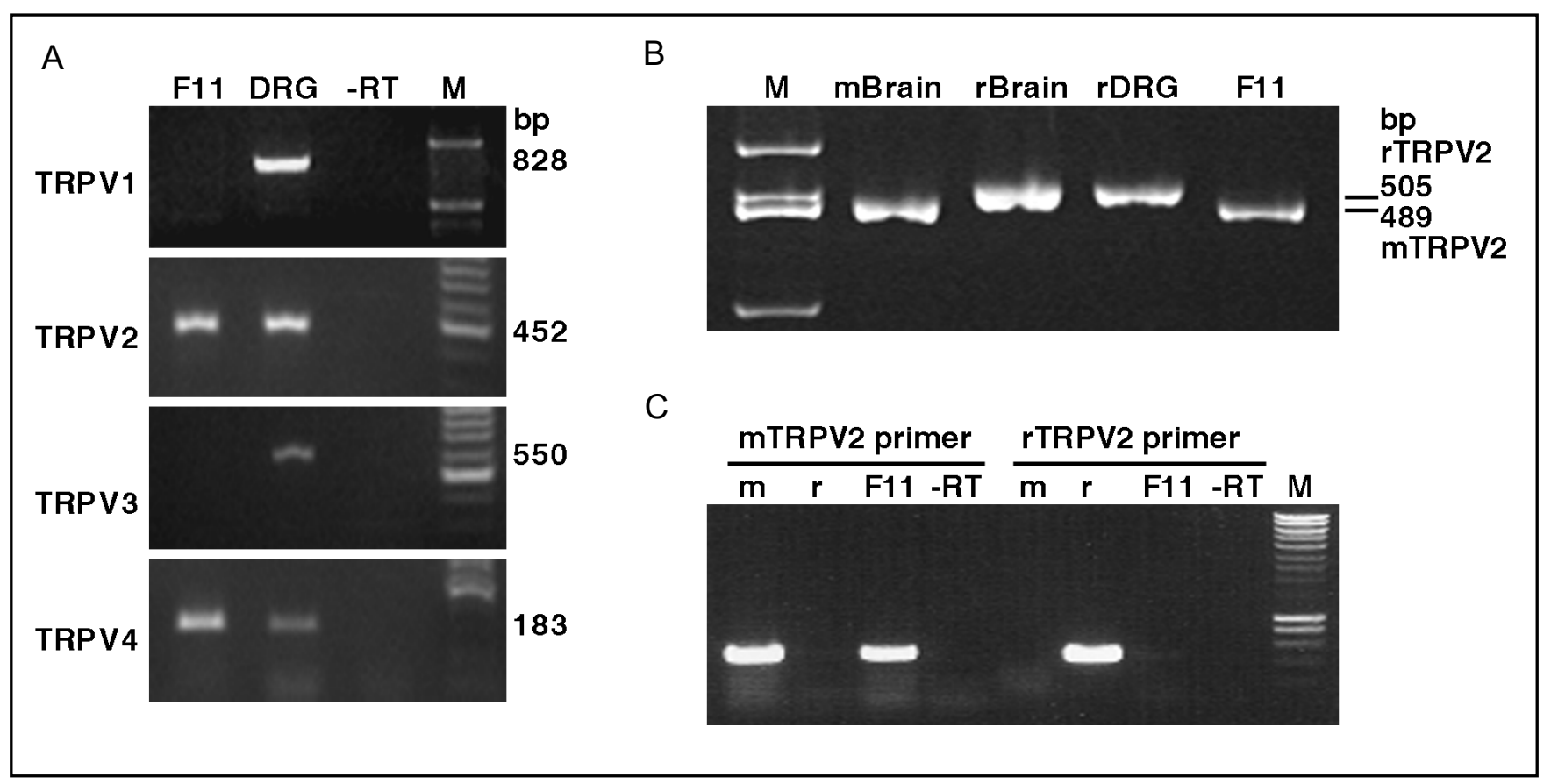

Fig. 1. RT-PCR analysis of TRPV1, TRPV2, TRPV3 and TRPV4 expression in F-11 cells and DRG. (A) Using gene-specific primers, TRPV2 and TRPV4 transcripts are detected in F-11 cells as well as in rat DRG. TRPV1 mRNA, highly expressed in DRG, and TRPV3 mRNA, expressed at lower levels in DRG, are absent from F-11 cells. As a negative control, reverse transcriptase was omitted from the reaction (-RT). (M, 100bp DNA ladder). (B) After amplification of the 5' end of the TRPV2 coding sequence, PCR products were separated on a $6 \%$ nondenaturing polyacrylamide gel stained with ethidium-bromide. A single band of $489 \mathrm{~kb}$ is visible in extracts of mouse brain,

TRPV2 immunoreactivity was located on the cell membrane as well as in the cytoplasm of F-11 cells. As expected, specific immunostaining for TRPV1 was absent from F-11 cells (Fig. 3). Using the same antibodies, TRPV2 and TRPV1 immunoreactivity was observed in different subpopulations of cultured DRG neurons (Fig. $3 \mathrm{C}, \mathrm{D})$ as described previously [10]. To further differentiate TRPV2- and TRPV1-expressing DRG subpopulations, we performed double immunofluorescence using confocal laser scanning microscopy for TRPV2 (Fig. 4, A-C) or TRPV1 (Fig. 4, D-F) with isolectin IB4, a marker for small diameter nociceptive afferents known to express TRPV1. TRPV2 immunoreactivity was located in a large-sized subpopulation of IB4-negative DRG neurons mainly in the cytoplasm (Fig. 4C). As expected, TRPV1 was predominantly expressed in a while TRPV2 transcripts in rat brain or rat DRG are slightly larger $(505 \mathrm{~kb})$. In F-11 cell extracts, only the mouse-specific 489-kb band is present (M, 100-bp DNA ladder). (C) PCR analysis of genomic DNA isolated from F-11 cells. Specific primers for the exon 3-intron III region of the mouse TRPV2 gene yield a 486-bp amplicon in PCR reactions with genomic DNA from F11 cells (F-11) and mouse genomic DNA (m), but not rat genomic DNA (r). Rat specific primers produce a 474-bp amplicon specific of the exon 1 - intron I region of the rat TRPV2 gene only in PCR reactions with rat genomic DNA. The rat TRPV2 gene is not detected in genomic DNA from F-11 cells or mouse tissue.

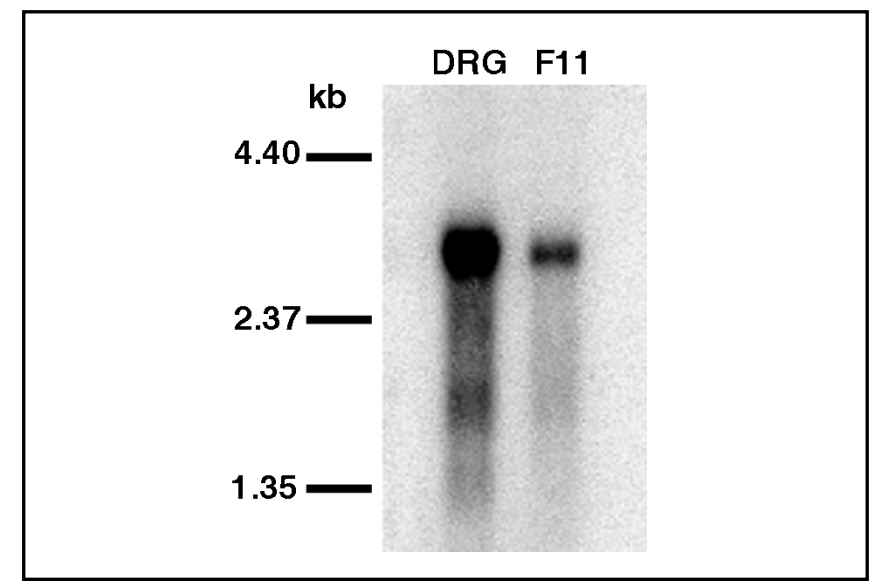

Fig. 2. Northern analysis of TRPV2 expression in F-11 cells and rat DRG. A single $2.7 \mathrm{~kb}$ TRPV2 transcript was detected in $1 \mu \mathrm{g}$ of poly(A) mRNA extracted from F-11 cells and rat DRG using a ${ }^{32} \mathrm{P}$-labeled riboprobe. Note that the abundance of TRPV2 mRNA is somewhat lower in F-11 than in DRG extracts. The position of the RNA size marker is shown on the left. Exposure time was $60 \mathrm{~min}$. 
Fig. 3. Detection of TRPV2 and TRPV1 proteins in F-11 and cultured DRG cells. TRPV2 immunostaining is located in the cytoplasma and at the cell membrane of F-11 cells (A). TRPV2 protein is also present in a subpopulation of cultured rat DRG neurons mainly of medium size (C). Specific staining for TRPV1 is absent in F-11 cells (B), but present in cultured DRG cells (D). The bar indicates $10 \mu \mathrm{m}$.
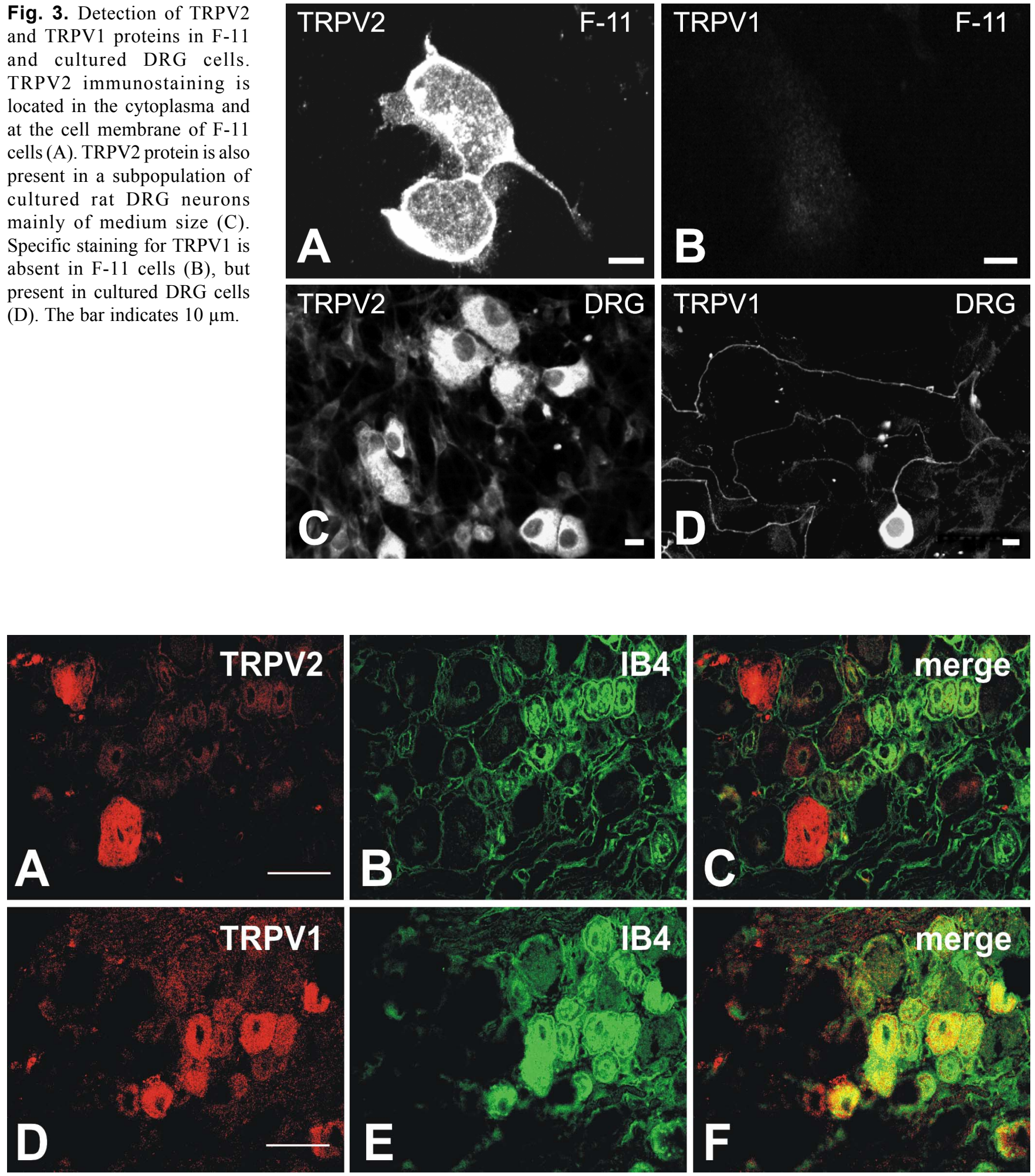

Fig. 4. TRPV2 and TRPV1 expression in separate subpopulations of primary afferent neurons. Double immunofluorescence for TRPV2 (A-C) or TRPV1 (D-F) with IB4 reveals that TRPV2 and TRPV1 are expressed in two distinct subpopulations of the dorsal root ganglion. TRPV2 protein is located in large-sized neurons of DRG (A), which are IB4 negative $(B, C)$. TRPV1 is predominantly expressed in the smallsized, IB4-positive subpopulation (E-F). Bars indicate $50 \mu \mathrm{m}$. 


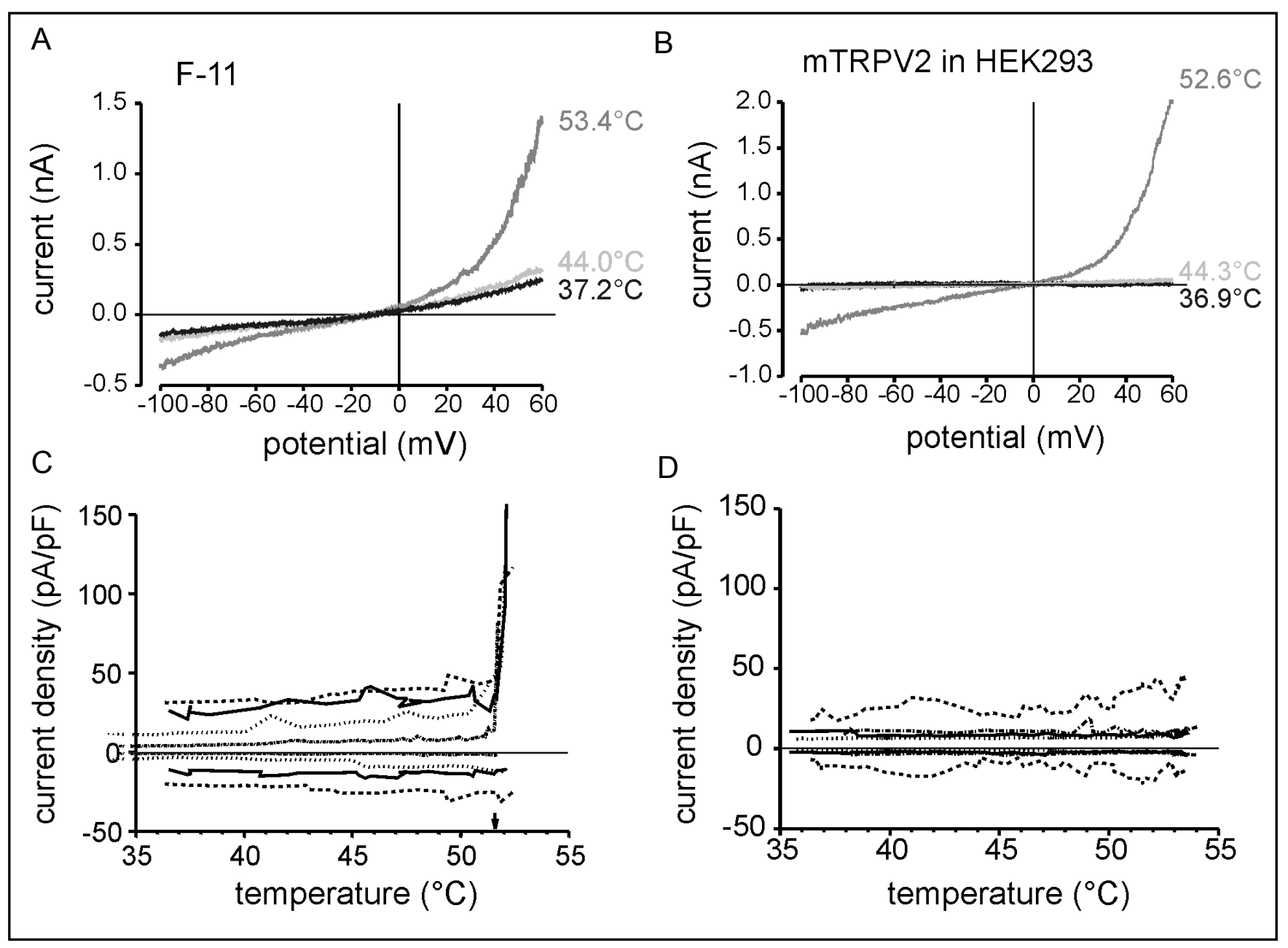

Fig. 5. Electrophysiological characteristics of TRPV2 in F-11 and HEK293 cells. Current-voltage relations for heat-evoked currents in F-11 cells (A) and mouse TRPV2 transiently transfected in HEK293 cells are depicted (B). Current density profiles of 4 individual F-11 cells were determined at $\pm 60 \mathrm{mV}$ with voltage ramps. The mean temperature threshold of $51.6^{\circ} \mathrm{C}$ $(n=15)$ for heat-evoked activation is indicated by an arrow (C). In the presence of $10 \mu \mathrm{M}$ ruthenium red inward and outward current density profiles of 4 representative F-11 cells are shown over the temperature (D). subpopulation of small IB4 positive cells (Fig. 4F) indicating that TRPV1 and TRPV2 expressing cells represent two distinct subpopulations of the rat DRG in vivo as well.

Functional characteristics of TRPV2 in the F-11 cell line

To address the question of functional expression of TRPV2 in F-11 cells electrophysiological experiments were performed. Before verifying the heat sensory function, the steady-state current-voltage relation of isolated F-11 cells was analyzed by using the patch-clamp technique. Under the experimental conditions employed, F-11 cells were not coupled electrically. The membrane capacitance of F-11 cells in the conventional whole-cell mode was $25.9 \pm 2.3 \mathrm{pF}(\mathrm{n}=15)$. Larger cells with a membrane capacitance $>44 \mathrm{pF}$ were not included in the analysis.

Exposure to temperature ramps from $37^{\circ} \mathrm{C}$ to $54^{\circ} \mathrm{C}$ induced an increase in inward and outward currents with a threshold of $51.6 \pm 0.2^{\circ} \mathrm{C}$. In 8 out of 15 cells measured, a reduction of currents was observed when temperature ramps were reversed from $54^{\circ} \mathrm{C}$ to $37^{\circ} \mathrm{C}$. Cells without current reduction were most likely damaged by $\mathrm{Ca}^{2+}$ 
influx or depolarization. The heat-evoked current-voltage relationship showed a strong outward rectification with a reversal potential at $-10.8 \pm 1.6 \mathrm{mV}(\mathrm{n}=14)$. The effects of heat application at $37^{\circ} \mathrm{C}, 44^{\circ} \mathrm{C}$ and $53^{\circ} \mathrm{C}$ on the steadystate current-voltage relationship are illustrated in Fig. $5 \mathrm{~A}$. In all cases, there was a slight increase of outward and inward currents from $37^{\circ} \mathrm{C}$ to $49^{\circ} \mathrm{C}$. These endogenous currents were not blocked by ruthenium red (Fig. 6A).

Nifedipine $(10 \mu \mathrm{M})$ a blocker of voltage-operated $\mathrm{Ca}^{2+}$ channels did not affect currents during depolarising steps to $0 \mathrm{mV}(\mathrm{n}=9)$, (data not shown).

To compare TRPV 2 channel properties in F-11 cells with those in a heterologous expression system, we transfected HEK293 cells with $2 \mu \mathrm{g}$ of TRPV2 cDNA cloned from F-11 cells together with $100 \mathrm{ng}$ of a reporter plasmid to control for transfection efficiency. After 48 hours measurements were performed under the same conditions in 10 separate transfection experiments. The difference between the reversal potentials of F-11 cells and transfected HEK293 cells was not statistically significant $(P=0.21)$. The mean temperature threshold was $51.3 \pm 0.6^{\circ} \mathrm{C}$, and did not differ between F-11 cells and mouse TRPV2-transfected HEK293 cells. To compare the heat-induced currents of single F-11 cells, currents densities were calculated at $\pm 60 \mathrm{mV}$ by applying voltage ramps. Four original recordings are depicted in Fig. 5C and D to illustrate the variety of thermal response behaviour of F-11 cells. However, it should be noted that, in contrast to F-11 cells, only 3 out of 142 transfected HEK293 cells displayed a heat-evoked current-voltage relationship with strong outward rectification and a reversal potential of $-6.1 \pm 1.5 \mathrm{mV}$ similar to that observed in F-11 cells (Fig. 5B). Such a low response rate was unexpected, especially since every F-11 cell, from which we successfully recorded, responded to heat.

Heat-activated currents could be reduced dosedependently by ruthenium red (Fig. 6A). Already at $100 \mathrm{nM}$, we observed a reduction of outward and inward current densities from $56.1 \pm 13.1 \mathrm{pA} / \mathrm{pF}$ to $35.4 \pm 15.6$ $\mathrm{pA} / \mathrm{pF}$ and from $-17.2 \pm 4.8 \mathrm{pA} / \mathrm{pF}$ to $-8.6 \pm 2.1 \mathrm{pA} / \mathrm{pF}$, respectively. At a concentration of $10 \mu \mathrm{M}$ ruthenium red, outward $(12.4 \pm 3.4 \mathrm{pA} / \mathrm{pF}, P=0.01)$ and inward $(-4.7 \pm$ $1.6 \mathrm{pA} / \mathrm{pF}, P=0.04)$ current densities were significantly reduced (Fig. 5D). Thus, these measurements are in agreement with the previously published dose response curve for ruthenium red inhibition of TRPV2- transfected oocytes [10]. Application of $100 \mu \mathrm{M}$ capsaicin did not affect inward and outward currents of F-11 $(n=13)$ and

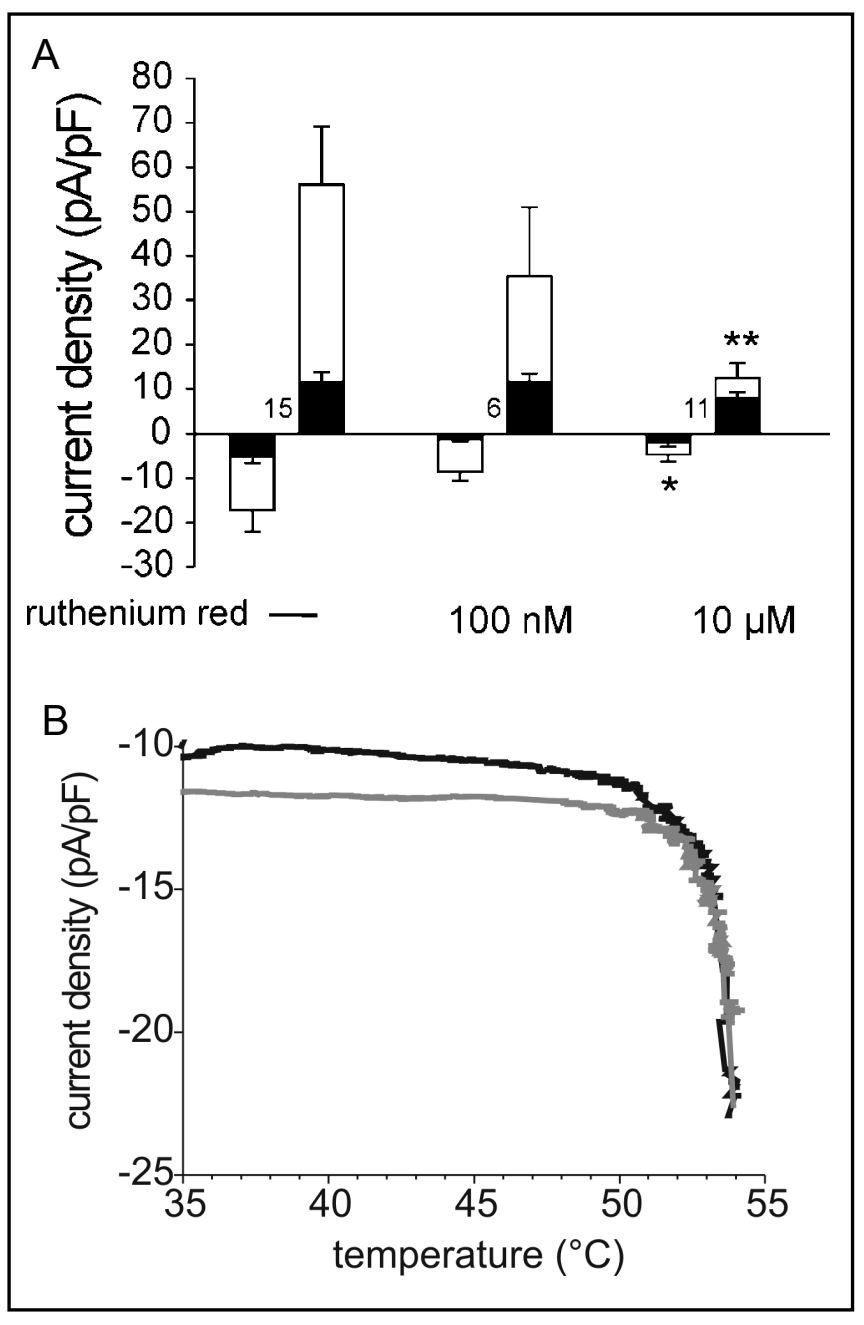

Fig. 6. Pharmacology of TRPV2 in F-11 cells. (A) Comparison of inward and outward current densities in the absence and presence of $100 \mathrm{nM}$ and $10 \mu \mathrm{M}$ ruthenium red at $37^{\circ} \mathrm{C}$ and $53^{\circ} \mathrm{C}$. Filled bars show mean inward and outward current densities at a temperature of $37^{\circ} \mathrm{C}$. Open bars represent mean current densities at $53^{\circ} \mathrm{C}$. Asterisks denote significant suppression with ruthenium red at $53^{\circ} \mathrm{C}$. The number of cells measured is indicated above the bars. Data are shown as means \pm SEM. (B) Comparison of current density temperature profiles measured at a holding potential of $-60 \mathrm{mV}$ under control conditions (grey line) and in the presence of $100 \mu \mathrm{M} 2$-APB (black line).

mouse TRPV2-expressing HEK293 cells $(\mathrm{n}=12)$, yet increased inward and outward currents in TRPV1expressing cells $(n=5)$. Since 2-aminoethoxydiphenyl borate (2-APB) has recently been proposed as a chemical ligand that activates TRPV3 and other TRPV channels $[19,20]$, we examined its effects on noxious heat responses in F-11 cells. There was no significant 
difference $(P=0.47)$ between the mean temperature threshold in the presence of $100 \mu \mathrm{M} 2$-aminoethoxydiphenyl borate (2-APB) with $51.4 \pm 0.4^{\circ} \mathrm{C}$ $(\mathrm{n}=7)$ and the control mean temperature threshold with $51.0 \pm 0.4^{\circ} \mathrm{C}(\mathrm{n}=6)$ acquired with the temperature ramp and a holding potential of $-60 \mathrm{mV}$. Representative recordings are illustrated in Fig 6B.

In aggregate, these results suggest that the heatevoked currents measured in F-11 cells are mediated by functionally expressed TRPV2 channels at the plasma membrane.

\section{Discussion}

The present study demonstrates that the neuronal sensory cell line F-11 expresses the temperature-sensitive non-selective ion channel TRPV2 with all typical functional characteristics of the high-threshold noxious heat-activated channel described for type I noxious heatsensitive primary afferents. The high temperature threshold $>51^{\circ} \mathrm{C}$, outward rectification, a reversal potential near $0 \mathrm{mV}$ and ruthenium red sensitivity strongly suggest the functional expression of TRPV2 in the cell membrane of F-11 cells. These electrophysiological properties were originally characterized in HEK293 cells and oocytes transfected with rat TRPV2 [10]. Given the problems of recording currents at high temperatures in cell lines, we did not establish a complete dose response curve for ruthenium red inhibition of TRPV2 in F-11 cells, which was originally performed in an oocyte expression system [10], and therefore limited our measurements to 2 concentrations. Inhibition at $100 \mathrm{nM}$ and $10 \mu \mathrm{M}$ is compatible with a proposed IC50 of $0.62 \mu \mathrm{M}$ [10]. Whether the potentiation by repeated heat pulses, so far only demonstrated in the oocyte expression system [10], is a general property of TRPV2 channels, is still unclear. Repeated heat pulses to temperatures necessary to activate TRPV2 on F-11 cells caused cell damage, e.g. leakage and the loss of seal information and, therefore, we have no further evidence for the sensitization or desensitization of endogenously expressed TRPV2 channels by repeated heat activation. Our success rate to analyze HEK293 cells expressing recombinant TRPV2 turned out to be quite low. Other laboratories have also reported difficulties to measure heat-induced currents mediated by TRPV2 in HEK293 cells indicating that functional properties of TRPV2 may depend on endogenous factors only present in the native neuronal

Functional TRPV2 Channels in F-11 Cells environment [4]. Indeed, every F-11 cell, from which we successfully recorded, showed a TRPV2-like thermal response. This may imply that TRPV2 is homogenously expressed among F-11 cells, although we cannot exclude the possibility that some of the non-recordable F-11 cells may lack TRPV2 expression.

TRPV2 was the only noxious heat-sensitive TRPV channel found in this study to be endogenously expressed by F-11 cells. We obtained no evidence for an expression of the capsaicin-sensitive TRPV1 in F-11 cells which is in line with results provided by others [21]. In light of the fact that F-11 and HEK293 cells transfected with the TRPV2 cDNA were capsaicin-insensitive, the previously reported modulation of $\mathrm{Ca}^{2+}$ currents in F-11 cells by capsaicin is somewhat puzzling [12]. Our RT-PCR analysis also revealed the expression of TRPV4 (also known as VROAC or OTRPC4), another capsaicininsensitive channel. TRPV4 has been reported to be activated by warm temperatures $\sim 27-35^{\circ} \mathrm{C}$ in heterologous expression systems [22,23]. So far there is no evidence that TRPV4 is involved in thermal nociception. The temperature threshold in F-11 cells conforms to that recorded in heterologously expressed TRPV2 channels, but not to the threshold of TRPV4 or other members of the TRPV family. To what extent TRPV4 exhibits temperature sensitivity in F-11 cells remains to be shown. The absence of TRPV 3 and TRPV1 expression in F-11 cells as revealed by RT-PCR conforms to the segregation of TRPV1/TRPV3 and TRPV2 expression in dorsal root ganglia in situ. In this study we have shown TRPV1 immunoreactivity in, and the absence of TRPV2 protein from IB4-positive DRG neurons, thus supporting previous observations $[5,11,24$, 25]. Typically, TRPV2 is seen in medium to large sized DRG neurons most likely representing type I AMH nociceptors, transmitting noxious heat responses rapidly to the $\mathrm{CNS}$, and in non-nociceptive $\mathrm{A} ß$-afferents, whereas TRPV1 is restricted to small to medium sized type II AMH neurons primarily involved in the processing of inflammatory pain. Recent experimental evidence from TRPV1 deficient mice has questioned an essential role of TRPV1 and TRPV2 for noxious heat responses in nociceptors [26]. This statement was based on the observation that cultured DRG neurons of TRPV1 deficient mice in which no immunostaining for TRPV2 is found still responded to noxious heat. The authors argued that additional noxious heat-responsive channels must exist. However, this only holds true if the possibilty of an underestimation of TRPV2 expression can be excluded. 
It could well be that the heat responsive TRPV1 deficient DRG neurons indeed express low levels of TRPV2 that escaped the immunocytochemical detection. The issue as to whether other channels than TRPV1 or TRPV2 exist will be best solved by demonstrating that TRPV1/TRPV2 double knockout mice are able to detect noxious heat. Given the theoretical possibility of noxious heat sensitive channels beyound TRPV1 and TRPV2, respectively, we have to consider that such a still speculative third channel with identical functional properties of TRPV2 might also contribute to the TRPV2 characteristic functional profile of the F-11 cell line demonstrated in the present study.

Regardless of additional heat noxious channels, the important role of TRPV1 in the processing of inflammatory pain and other chronic pain states as demonstrated with TRPV1 deficient mice is beyond any doubt [27]. Accordingly, the specific role of TRPV2 in thermonociception should be resolvable once mice lacking TRPV2 are available.

The activation of TRPV1 by non-thermal stimuli including several chemical substances such as capsaicin, protons and endocannabinoids has stimulated the search for new compounds activating TRPV channels. TRPV4 was shown to be activated by arachidonic acid metabolites and phorbol derivatives [22] and 2-APB has recently been identified as chemical activator of TRPV3 and possibly other TRPV channels. At present it is a matter of debate whether TRPV2 is activated by 2-APB. While Hu et al. [19] observed an activation of TRPV2 in the presence of $3 \mathrm{mM} 2-\mathrm{APB}$, we failed to observe an effect of 2-APB. Incubation ofF-11 cells with $100 \mu \mathrm{M} 2$-APB did not affect the mean temperature threshold or cause a significant change in current density with a holding potential of -60 $\mathrm{mV}$. Experiments at $3 \mathrm{mM}$ 2-APB were unsuccessful because of problems dissolving the compound. Our findings are in line with results by Chung et al. studying the effect of 2-APB on heterologously expressed TRPV2 [20]. We propose that F-11 cells represent a useful in vitro system to identify novel chemicals activating TRPV2.

In a previous conference report we provided evidence for the isolation of a full-length TRPV2 cDNA from F-11 cells homologous to rat [28]. However, our subsequent sequence analysis of several cDNAs and RTPCR using mouse and rat specific primers revealed that F-11 cells predominantly express mouse TRPV2 transcripts. This was further confirmed by genomic PCR using gene-specific primers. Rat and mouse TRPV2
mRNAs are $93 \%$ identical and display $82 \%$ homology at the protein level. Although rat TRPV2 lacks 5 amino acids at the $\mathrm{N}$-terminus when compared to its mouse orthologue, both proteins cannot be distinguished by immunoblotting. Following our initial conference report Jahnel and coworkers recently confirmed our observation of TRPV2 expression in F-11 cells independently [16]. They reported the presence of both rat and mouse TRPV2 in individual F-11 cells. Since TRPV2 was also expressed by the F-11 parental cell line N18TG2 it was suggested that TRPV2 in F-11 cells was of mouse origin. Furthermore, these authors found endogenous TRPV2 immunoreactivity restricted to the cytoplasm, whereas rat TRPV2 overexpressed in F-11 cells seemed to be located on the plasma membrane and in neurites. These findings contrast with our immunocytochemical results showing TRPV2 immunoreactivity in F-11 cells in the cytoplasm as well as at the plasma membrane. These discrepancies may be explained by subtle differences in culture conditions known to alter morphological features and neuronal phenotype or by using different passages. Nevertheless, our electrophysiological results using the whole-cell patch-clamp technique strongly argue for our view that TRPV2 channels are indeed transported to and inserted into the plasma membrane, which is further supported by our immunocytochemical results.

The tissue distribution of TRPV2 and activation by non-thermal stimuli suggest TRPV2 functions beyond temperature sensation. In fact, Kanzaki and coworkers identified TRPV2 as a calcium-permeable channel cloned from Balb/c3T3 cells which was regulated by insulin-like growth factor (IGF-I) and therefore named growth factor regulated channel (GRC) suggesting a role in the regulation of cell growth [29]. They reported that TRPV2 transfected in CHO-K1 cells was constitutively active at RT following treatment with insulin-like growth factor for a few minutes, and displayed only slightly increased currents in response to noxious heat. This finding is in contrast to our observation in the DRG hybridoma F-11, which represents an endogenous neuronal expression system, where TRPV2 does not show constitutive activity, but can be activated by noxious heat.

In transfected CHO-K1 cells TRPV2 appeared to be localized mainly in intracellular compartments under basal conditions. Upon stimulation with IGF-I and other mitogens a translocation to the plasma membrane was observed [29]. However, own investigations in F-11 cells showed no effect of IGF-I on subcellular distribution of TRPV2 (unpublished observation). 
Soluble co-factors to mediate heat responsiveness and posttranslational modification of TRPV2 have been proposed. In this context it is noteworthy that phosphorylation of TRPV1 by protein kinase $\mathrm{C}$ results in channel activation at room temperature [30]. The issue as to whether TRPV2 undergoes similar posttranslational modifications such as phosphorylation in a neuronal environment, could be addressed by employing the F-11 cells which express TRPV2 constitutively.

In conclusion, we established the F-11 cell line as new in vitro model to study the functional properties of the noxious heat-transducing channel TRPV2 and possibly some properties of $A \delta$-mechano- and heat-sensitive (AMH) neurons expressing TRPV2 in situ. The cell biology of TRPV2 including its transcriptional regulation and intracellular signaling cascades can now be investigated in a readily accessible neural environment.

\section{Acknowledgements}

Part of this work was presented at the Annual Society of Neuroscience meeting: (Bender, F.L.P., Mederos y Schnitzler, M., Li, Y., Ji, A., Weihe, E., Gudermann, T. \& Schafer, M.K. (2002) Expression and functional characterization of the vanilloid receptor-like TRP channel VRL-1 in the primary sensory cell line F11. Program no. 48.23, 2002 Abstract Viewer and Itinerary Planner. Society for Neuroscience, Washington, DC.).

We gratefully acknowledge expert technical assistance of H. Reichert-Preibsch and B. Wiegand. This work was supported by the Bundesministerium für Bildung und Forschung (BMB + F; 01 GG 9818/0 to E.W: and MKHS) and Deutsche Forschungsgemeinschaft (DFG; SFB 297).

\section{References}

1 Montell C, Birnbaumer L, Flockerzi V:

The TRP channels, a remarkably functional family. Cell 2002;108:595598.

2 Clapham DE: TRP channels as cellular sensors. Nature 2003;426:517-524.

-3 Gunthorpe MJ, Benham CD, Randall A, Davis JB: The diversity in the vanilloid $>9$ (TRPV) receptor family of ion channels. Trends Pharmacol Sci 2002;23:183-191.

4 Benham CD, Gunthorpe MJ, Davis JB: TRPV channels as temperature sensors. Cell Calcium 2003;33:479-487.

$\checkmark 5$ Caterina MJ, Schumacher MA, Tominaga M, Rosen TA, Levine JD, Julius D: The capsaicin receptor: a heat-activated ion channel in the pain pathway. Nature 1997;389:816-824.

6 Zygmunt PM, Petersson J, Andersson DA, Chuang H, Sorgard M, Di Marzo V, Julius D, Hogestatt ED: Vanilloid receptors on sensory nerves mediate the vasodilator action of anandamide. Nature 1999;400:452-457.

7 Hwang SW, Cho H, Kwak J, Lee SY, Kang CJ, Jung J, Cho S, Min KH, Suh YG, Kim D, Oh U: Direct activation of capsaicin receptors by products of lipoxygenases: endogenous capsaicin-like substances. Proc Natl Acad Sci U S A 2000;97:61556160 .
Smith GD, Gunthorpe MJ, Kelsell RE, Hayes PD, Reilly P, Facer P, Wright JE, Jerman JC, Walhin JP, Ooi L, Egerton J, Charles KJ, Smart D, Randall AD, Anand P, Davis JB: TRPV3 is a temperaturesensitive vanilloid receptor-like protein. Nature 2002;418:186-190.

Treede RD, Meyer RA, Raja SN, Campbell JN: Evidence for two different heat transduction mechanisms in nociceptive primary afferents innervating monkey skin. J Physiol 1995;483:747758.

Caterina MJ, Rosen TA, Tominaga M, Brake AJ, Julius D: A capsaicin-receptor homologue with a high threshold for noxious heat. Nature 1999;398:436-441. Ahluwalia J, Rang H, Nagy I: The putative role of vanilloid receptor-like protein-1 in mediating high threshold noxious heatsensitivity in rat cultured primary sensory neurons. Eur J Neurosci 2002;16:14831489.

-12 Kusano K, Gainer H: Modulation of voltage-activated $\mathrm{Ca}$ currents by paininducing agents in a dorsal root ganglion neuronal line, F-11. J Neurosci Res 1993;34:158-169.

Platika D, Baizer L, Fishman MC: Sensory neurons "immortalized" by fusion with neuroblastoma cells. Trans Assoc Am Physicians 1985;98:301-304.
Francel PC, Harris K, Smith M, Fishman MC, Dawson G, Miller RJ: Neurochemical characteristics of a novel dorsal root ganglion X neuroblastoma hybrid cell line, F-11. J Neurochem 1987;48:1624-1631. Boland LM, Dingledine R: Expression of sensory neuron antigens by a dorsal root ganglion cell line, F-11. Brain Res Dev Brain Res 1990;51:259-266.

16 Jahnel R, Bender O, Munter LM, Dreger M, Gillen C, Hucho F: Dual expression of mouse and rat VRL-1 in the dorsal root ganglion derived cell line F-11 and biochemical analysis of VRL-1 after heterologous expression. Eur J Biochem 2003;270:4264-4271.

17 Stumm R, Culmsee C, Schafer MK, Krieglstein J, Weihe E: Adaptive plasticity in tachykinin and tachykinin receptor expression after focal cerebral ischemia is differentially linked to gabaergic and glutamatergic cerebrocortical circuits and cerebrovenular endothelium. J Neurosci 2001;21:798811.

Varoqui H, Schafer MK, Zhu H, Weihe E, Erickson JD: Identification of the differentiation-associated $\mathrm{Na}+$ /PI transporter as a novel vesicular glutamate transporter expressed in a distinct set of glutamatergic synapses. J Neurosci 2002;22:142-155. 
19 Hu HZ, Gu Q, Wang C, Colton CK, Tang J, Kinoshita-Kawada M, Lee LY, Wood JD, Zhu MX: 2-aminoethoxydiphenyl borate is a common activator of TRPV1, TRPV2, and TRPV3. J Biol Chem 2004;279:35741-35748.

20 Chung MK, Lee H, Mizuno A, Suzuki M, Caterina MJ: 2-aminoethoxydiphenyl borate activates and sensitizes the heatgated ion channel TRPV3. J Neurosci 2004;24:5177-82.

21 Jahnel R, Dreger M, Gillen C, Bender O, Kurreck J, Hucho F: Biochemical characterization of the vanilloid receptor 1 expressed in a dorsal root ganglia derived cell line. Eur J Biochem 2001;268:5489-5496.

22 Watanabe H, Davis JB, Smart D, Jerman JC, Smith GD, Hayes P, Vriens J, Cairns W, Wissenbach U, Prenen J, Flockerzi V, Droogmans G, Benham CD, Nilius B: Activation of TRPV4 channels (hVRL2/mTRP12) by phorbol derivatives. J Biol Chem 2002;277:13569-77.
23 Guler AD, Lee H, Iida T, Shimizu I, Tominaga M, Caterina M: Heat-evoked activation of the ion channel, TRPV4. J Neurosci 2002;22:6408-6414.

24 Helliwell RJ, McLatchie LM, Clarke M, Winter J, Bevan S, McIntyre P: Capsaicin sensitivity is associated with the expression of the vanilloid (capsaicin) receptor (VR1) mRNA in adult rat sensory ganglia. Neurosci Lett 1998;250:177-180.

25 Tominaga M, Caterina MJ, Malmberg AB, Rosen TA, Gilbert H, Skinner K, Raumann BE, Basbaum AI, Julius D: The cloned capsaicin receptor integrates multiple pain-producing stimuli. Neuron 1998;21:531-543.

Woodbury CJ, Zwick M, Wang S, Lawson JJ, Caterina MJ, Koltzenburg M, Albers KM, Koerber HR, Davis BM: Nociceptors lacking TRPV1 and TRPV2 have normal heat responses. J Neurosci 2004;24:6410-5
27 Caterina MJ, Leffler A, Malmberg AB, Martin WJ, Trafton J, Petersen-Zeitz KR, Koltzenburg M, Basbaum AI, Julius $\mathrm{D}$ : Impaired nociception and pain sensation in mice lacking the capsaicin receptor. Science 2000;288:306-13.

28 Bender FLP, Mederos y Schnitzler M, Li Y, Ji A, Weihe E, Gudermann T, Schafer MK-H: Expression and functional characterization of the vanilloid receptor-like TRP channel VRL-1 in then primary sensory cell line F-11(eds): Abstract Viewer and Itinerary Planner. Washington, D.C., Society for Neuroscience, 2002. pp program no. 48.23.

Kanzaki M, Zhang YQ, Mashima H, Li L, Shibata H, Kojima I: Translocation of a calcium-permeable cation channel induced by insulin-like growth factor-I. Nat Cell Biol 1999;1:165-170.

Vellani V, Mapplebeck S, Moriondo A, Davis JB, McNaughton PA: Protein kinase $\mathrm{C}$ activation potentiates gating of the vanilloid receptor VR1 by capsaicin, protons, heat and anandamide. J Physiol 2001;534:813-825. 